\title{
Aracnologias - AS tecituras de PENÉlopE
}

\author{
Cristina M. T. Stevens $* 1$ \\ Universidade de Brasília
}

É do esquecimento que a memória se constitui Lucia Castelo Branco. A mulher escrita

\begin{abstract}
RES U M O
Análise da personagem Penélope, de Homero, e a transformação ousada de Joyce dessa representação clássica da fidelidade feminina em Molly Bloom, a esposa infiel, sexualizada, trivial, lírica. Essas duas personagens são comparadas com sua mais recente recriação em The Penelopiad (2005), da escritora canadense Margaret Atwood. Uma importante categoria analítica dos estudos feministas e de gênero, a questão da voz é enfatizada na presente análise; essa personagem feminina é objeto da narrativa masculina (A Odisseia e Ulisses), mas no romance de Atwood essa personagem é sujeito de sua narrativa, elaborando uma tecitura "penelopeana" transgressora da versão clássica. Focalizaremos também o poder do silêncio na narrativa de autoria feminina, através do monólogo interior de Molly e da voz que fala do mundo dos mortos em The Penelopiad. Os conceitos de "abjeto" e "linguagem semiótica" de Kristeva são base para nosso trabalho, o qual problematiza a aparente imagem de passividade dessas mulheres que buscam o controle sobre suas vidas.
\end{abstract}

\section{PALAVRAS - CHAVE}

Literaturas em língua inglesa, gênero, psicanálise

Precisamente vinte e um anos depois de ter defendido minha tese de doutorado sobre Ulysses de James Joyce, retorno a essa obra-prima da literatura e verifico que o fascínio que me motivou a trabalhar com esse romance continua forte. Entretanto, não me surpreende que Ulysses continua aberto para novas perspectivas, neste caso, meu interesse na área de estudos feministas e de gênero, o que forneceu-me uma perspectiva diferente com a qual me reaproximo do romance. Meu objetivo no presente trabalho é desenvolver

\footnotetext{
*estevens@unb.br

${ }^{1}$ Agradeço à FINATEC/UnB, que viabilizou minha participação no Congresso The Novel and its Borders, realizado na Universidade de Aberdeen em julho/2008, onde este trabalho foi apresentado em sua versão em inglês.
} 
uma análise comparativa da personagem Penélope - do clássico épico de Homero - com Molly Bloom, a "Penelope" intrigante de Joyce. Esta comparação avança em direção a uma recriação contemporânea desta emblemática personagem feminina, desenvolvida pela escritora canadense Margaret Atwood em seu romance The Penelopiad (2005).

Um dos pontos que desenvolvo neste trabalho é a admirável contemporaneidade do romance de Joyce, apesar de sua localização específica no tempo e no espaço: Dublin, 1904. Como feminista, pensei inicialmente que deveria identificar traços reveladores da atitude misógina de Joyce na criação de sua personagem feminina mais famosa; entretanto, talvez isto limitasse o escopo de minha análise, sobretudo porque sabemos que a obra de Joyce não pode ser encapsulada em rótulos e categorias. Para Liv McMullen, "Através de Molly, Joyce se desvia radicalmente dos padrões patriarcais tradicionais que codificavam as mulheres naquele inicio de século [e] navega entre os pólos opostos de feministas e conservadores". ${ }^{2}$ Minha análise, portanto, focaliza a esplêndida transformação da exemplar esposa fiel de Homero em uma Penélope infiel, sexualizada, e também lírica: Molly Bloom. A reconstrução da mítica Penélope no romance de Atwood nos remete não apenas para Molly mas problematiza sobretudo a criação de Homero, tornando-a mais complexa - como se a Penélope de Joyce fosse o "missing link" entre a tradição clássica, patriarcal e sua versão contemporânea, feminista.

O intrigante monólogo Molly Bloom constitui o episódio final de Ulysses. Passeamos com a mente de Molly para tempos e espaços distintos, embora tempo e espaço estejam claramente marcados - o quarto do casal, nas primeiras horas do dia 17 de junho (1904). Molly não está limitada no tempo - podemos associá-la com o conceito de "tempo da mulher" elaborado por Julia Kristeva. ${ }^{3}$ Enquanto seu marido caminha por Dublin, redefinindo em termos paródicos as perambulações heroicas de Odisseu, a Penélope de Joyce desenvolve uma viagem interior - não menos importante - cujo movimento está associado com os movimentos da terra.

No final da épica de Homero, Ulysses e sua esposa vão juntos para o quarto. O Ulisses de Joyce também termina o dia - sua "viajem de aventuras" - na cama com sua esposa; entretanto, enquanto ele dorme profundamente, a mente de sua esposa está sobrecarregada de memórias e fantasias sexuais que constituem o elemento principal deste episódio. Ela começa a lembrar do passado, de sua vida monótona em Gibraltar, o primeiro homem a cortejá-la; imediatamente seus pensamentos voltam-se para questões ligadas a sexo, quando ela descreve seu apetite sexual intenso, a tarde orgásmica que ela acaba de passar com seu amante Boylan e muitos outros amantes, reais ou fruto apenas de suas fantasias. Sua mente perambula brevemente por digressões de natureza religiosa, o que a leva a fantasiar sobre ligações sexuais com um padre. De volta ao presente,

\footnotetext{
${ }^{2}$ McMULLEN. Same old Penelope: feminist analysis of Molly's soliloquy in Ulysses, p. 3. Neste trabalho, as traduções dos textos publicados em língua inglesa são de minha autoria.

${ }^{3}$ Em "Women's time", Kristeva desenvolve um conceito de tempo a partir da perspective da maternidade e reprodução - "fornecendo uma medida especifica que essencialmente contém repetição e eternidade" - o qual ela distingue do tempo linear da história e da linguagem; esta "presença maciça de uma temporalidade monumental" estaria ligada à subjetividade da mulher, em contraste com a obsessão masculina em controlar o tempo linear, no qual ela identifica "uma estrutura verdadeiramente escravizante”. KRISTEVA. Women's time, p. 862-3.
} 
reclamações de natureza maternal vêm à sua mente. Ela também reflete sobre sua aparência pessoal, sobre a qual sente-se um pouco insatisfeita; entretanto, este desconforto com seu corpo não dura muito.

Molly percebe que sua menstruação chegou, o que lhe provoca extremo desconforto físico. Ela dirige-se para o urinol, e sua urina mistura-se ao sangue menstrual: "quero me levantar um minuto para ver se eu espera oh Jesus espera sim lá me veio a coisa sim mas isso é ou não é de afligir a gente é claro toda essa cutucação e metição e mexeção que ele fez em cima de mim agora". ${ }^{4} \mathrm{O}$ ciclo menstrual reforça a problemática da imanência da mulher, o que faz com que sua identidade seja sempre baseada em seu corpo e sua atividade reprodutiva. O comportamento livre de Molly também nos remete para a obsessão do homem com a castidade da mulher, em função da legitimidade do "Nome do Pai", como nos lembra Freud, Lacan e tantos outras construções discursivas patriarcais de ordem legal, religiosa, socioantropológica, etc. É importante enfatizar aqui o pensamento de Simone de Beauvoir sobre a maternidade como uma condição que limita o papel da mulher à imanência de sua função reprodutiva, ao passo que ao homem ficaram destinados as realizações transcendentes da cultura e do poder.

A substanciação/transubstanciação da urina e do sangue menstrual de Molly remete o leitor para o início do livro, quando Buck Milligan parodia as palavras de Jesus na última ceia: "Porque isto, ó bem-amados, é a autêntica Christina: corpo e alma, e sangue e chagas." ${ }^{5}$ Mas o sangue que aparece ao final do livro não é divino - é sangue de mulher, que nos dá o sangue em um urinol, não num cálice ritualístico que celebra o milagre de Jesus transformando água em vinho, vinho em sangue. Esta paródia fragiliza as verdades dogmáticas do cristianismo, assim como muitas outras grand recits que nos guiaram por muitos séculos, e que colocaram a mulher em uma posição inferior. Molly não se deixa prender na armadilha dos ciclos biológicos da mulher que a escravizaram por tanto tempo; ao contrário, ela os expõe sem vergonhas puritanas ou sentimento de culpa. A dicotomia clássica entre natureza/cultura, matéria/espírito, e a elevação platônica deste último foi reforçada pelo cristianismo; entretanto, não é assimilada por Joyce, que executa com mestria um "marriage of opposites" blakeano. Richard Ellmann explica que Penélope é o único episódio em Ulysses que não ilustra nenhuma arte, na estrutura complexa que Joyce criou para seu romance - a arte seria a própria natureza: "a filosofia se faz carne". 6 .

Molly não se envergonha de sua educação formal limitada, em contraste com a sabedoria acadêmica inútil e orgulhosa de Stephen. Sua sabedoria pragmática dá ao leitor uma perspectiva interessante, pois percebemos que muitas vezes ela consegue enxergar além do mundo intelectualizado e abstrato que os personagens masculinos constroem. Longe de ser apenas um ventríloco dos conceitos patriarcais sobre a mulher, o fluxo de consciência dessa personagem feminina irreverente expõe as contradições desses conceitos. Ela tem forte resistência a alguns postulados do catolicismo, que levaram ao desempoderamento da mulher; quando relembra suas experiências no confissionário, Molly questiona a autoridade masculina neste processo: "e que é que isso tinha que ver

\footnotetext{
${ }^{4}$ JOYCE. Ulisses, p. 835.

${ }^{5}$ JOYCE. Ulisses, p. 10.

${ }^{6}$ ELLMANN. Ulysses on the Liffey, p. 163.
} 
e você que maneira que ele disse eu esqueci não padre e eu sempre penso no verdadeiro padre que é que ele precisava saber quando eu já tinha confessado isso a Deus". ${ }^{7}$ Por que foi dado aos homens o poder de mediar o contato sagrado entre Deus e o ser humano? Por que às mulheres não foi garantido os mesmos privilégios? Estudos feministas têm trazido contribuições bastante esclarecedoras neste sentido. ${ }^{8}$ Ao satisfazer seus desejos sexuais de forma desafiadora, Molly também desafia um dos mais importantes preceitos da Igreja Católica, a qual defende a atividade sexual apenas para fins de procriação.

O solilóquio que constitui todo este episódio é completamente sem forma nem pontuação, uma inovação narrativa bastante ousada. Apesar de produzido por um autor, este monólogo interior de uma mulher nos faz pensar no conceito de ecriture feminine definido pelas feministas como uma escrita desestabilizadora, "uma escrita que é excessiva, fluida, que reproduz o prazer da música, reintroduz a materialidade da voz e re-explora o corpo". ${ }^{9}$ Em seu famoso ensaio "The Laugh of the Medusa", Hélène Cixous defende uma escrita "vulcânica" que seria desenvolvida pela mulher - "os labirintos, as escadas, o continente escuro", [para confrontar a] "litania da castração que é transmitida e genealogizada" pela tradução falocêntrica: "Ela deve escrever seu self, porque assim estaria criando uma nova forma de escrever que, quando o momento de sua liberação chegar, permitirá que ela processe as rupturas e transformações indispensáveis em sua história."10

Através de uma construção admirável de um autor masculino, entramos na mente desta personagem feminina multifacetada, (des)mistificada; ela já foi identificada com Calypso, Penélope, Gea Tellus. Ela é ao mesmo tempo a tentadora Maria Madalena da ideologia cristã tradicional, e a maternal Virgem Maria. Entretanto, ela vai muito além dessas associações patriarcais arquetípicas da mulher: ela é apenas Molly, que não pode ser encapsulada em definições, sobretudo em "regimes de verdade" patriarcais.

Em "Penélope", através de sua perspectiva geocêntrica/egocêntrica - pela autoridade de uma voz feminina - os personagens imortantes do romance são des/ reconstruídos. Quando lemos o episódio, voltamos para uma rica e caótica variedade de acontecimentos da vida de Molly, os quais foram narrados pelos personagens masculinos nos episódios anteriores. Assim como a Penélope de Homero, Molly é um objeto narrado pela voz masculina ao longo do romance: ela é insultada, desejada, criticada; entretanto, ao revisitar essas construções narrativas no monólogo interior de Molly, temos uma perspectiva bem diferente dos fragmentos de sua vida - sua infidelidade, seu ousado comportamento sexual, sua autoimagem, sua visão de seu marido, amigos, amantes, filhos, sua vida em geral e a daqueles ao redor dela - tudo transmutado num jogo enunciativo que evidencia a importância das variações determinadas pelo local de fala: não mais objeto de uma voz narrativa masculina como acontece durante todo o romance, Molly torna-se sujeito de seu discurso sobre ela mesma e sobre os demais personagens/ acontecimentos. Desta forma, Joyce desconstrói, com sua Penélope, as imagens tradicionais

\footnotetext{
${ }^{7}$ JOYCE, Ulisses, p. 801

${ }^{8}$ Ver, por exemplo, HARPER. When Women Were Priests, 1995.

${ }^{9}$ BRENNAN. Between Feminism and Psichoanalysis, p. 158.

${ }^{10}$ CIXOUS. The Laugh of the Medusa, p. 350.
} 
das mulheres como seres passivos, submissos, altruistas, assexuados, como fará também Atwood, criando uma Penélope para o terceiro milênio.

Apesar de Molly falar apenas consigo mesma, este silêncio acústico não torna suas palavras menos sonoras; a construção narrativa deste episódio nos remete ao conceito de linguagem semiótica, desenvolvido por Kristeva, a qual ela define como uma metalinguagem que é ao mesmo tempo sujeita a, e subversiva da, linguagem estruturada no simbólico uma linguagem que utiliza o simbólico precisamente para subvertê-lo: uma escrita que denuncia/renuncia a escrita. ${ }^{11}$ Esta metalinguagem está sempre consciente de sua provisionalidade discursiva.

Kristeva enfatiza a importância da fase pré-edipiana, pré-verbal, como a base de onde se origina o self e também o semiótico, que precede a identificação com o pai no domínio do simbólico, no estágio edípico muito explorado pela psicanálise. $\mathrm{Na}$ fase pré-edípica, ela explica, a criança existe em relação simbiótica com a mãe - no início está o útero, não a palavra. Entretanto, esta experiência fusional tem que ser reprimida - "separare = se parere", ou seja, de sua partição do corpo da mãe, o sujeito procede à sua parturição, à constituição do seu self. ${ }^{12}$

Como vimos brevemente, a fidelidade da Penélope de Joyce recebeu um tratamento radicalmente diferente daquele construído pela voz de Homero. Ellmann comenta sobre isto: "Penso que ele [Joyce] também ficou impressionado pela lenda, que Bacon reconta com ceticismo, sobre Penélope ter sido infiel a Ulisses, não com apenas um pretendente mas com todos eles, e o resultado deste 'acasalamento' em grande escala foi Pan, ou seja, a natureza universal." 13

O mito da mulher tentadora, infiel, criado pelo patriarcado, evidencia, em minha compreensão, uma obsessão de origem complexa e difusa que foi transmutada em tantas Evas e Dalilas, em personagens como Penélope, Clitmenestra, Madame Bovary, Ana Karenina, nossa enigmática Capitu, para citar apenas algumas dessas construções discursivas de autoria masculina. Essa clássica personagem de Homero tem provocado inúmeras discussões na contemporaneidade, sobretudo entre teóricas feministas que buscam desconstruir o ideal feminino que Penélope simboliza. A milenar Penélope, problematizada brilhantemente no romance de Joyce, é retomada por Atwood em The Penelopiad, o qual reconstrói o clássico paradigma patriarcal do espírito aventureiro e heroico do homem e da lealdade resignada da mulher a partir de uma voz autoral comprometida com os interesses da mulher.

No texto "Is Contemporary Women's Writing Computational? Unraveling Twenty-first Century Creativity with Penelope at her Loom”, Liedeke Plate nos lembra que a imagem de Penélope com seu tear é emblemática da criatividade das mulheres. A palavra grega para "unweaving" = analuô (analisar) ${ }^{14}$ está associada ao silencioso trabalho

\footnotetext{
${ }^{11}$ Em uma conferência internacional sobre sua obra - Secret Passages: Hélène Cixous on the Frontiers of Literature, organizado pelo Centre for Cultural Analysis, Theory and History of Leeds University (Nov. 2003), Cixous utiliza essas palavras para afirmar a noção derrideana, lacaniana, das limitações das repreentações linguísticas, simbólicas.

${ }^{12}$ LEMAIRE. Introdução a Lacan, p. 122

${ }^{13}$ ELLMAN. The Consciousness of Joyce, p. 29

${ }^{14}$ Em português, a palavra significaria "destecer" (weave significa "tecer").
} 
de Penélope, a qual espera o retorno do marido de forma aparentemente resignada, enquanto tece um manto para seu sogro, desfeito todas as noites. Esta estratégia inteligente mantém seus pretendentes à espera de sua decisão sobre o futuro esposo, o qual será escolhido após o término de seu trabalho. Desta forma, Penélope mantém com astúcia o controle sobre sua vida e sua posição de rainha de Ítaca, tecendo não apenas um "grande e delicado trabalho", ${ }^{15}$ mas sobretudo seu destino, quando finge aceitá-lo passivamente. Assim, na intimidade de seus aposentos, a silenciosa Penélope (des/re)faz a tecitura de sua vida (des/re) construindo o destino a ela reservado pela sociedade patriarcal: o casamento, a perda de autoridade e autonomia.

Lembrando Penélope, Arachne e Ariadne, Plate desenvolve a metáfora da tecelagem, recuperando a etimologia da palavra "texto" - do latim: textere (tecer) e enfatizando a importância de se "resgatar Penélope como representação da escrita feminina no século XXI". ${ }^{16}$ A legendária tecitura de Penélope, um trabalho criativo, silencioso e complexo, é rearticulada de forma diferente pela tecitura discursiva de Atwood, cuja Penélope recupera a tradição oral de "tecer" estórias: "Contar estórias não é uma arte nobre. Mulheres velhas fazem isto, mendigos perambulantes, cantores cegos, empregados, crianças - pessoas com tempo em suas mãos. ... Então irei tecer meu próprio fio." ${ }^{17}$

Assim como Molly, A Penélope de Atwood também está silenciosa no mundo simbólico, falologocêntrico do patriarcado. Ela verbaliza sua narrativa apenas depois de morta; entretanto, apesar de habitar o Hades, suas palavras demonstram sonoridade e empoderamento inimagináveis na Penélope homérica. Retomamos mais uma vez o conceito de linguagem semiótica já mencionado neste trabalho, tentando escutar o silêncio, tentando imaginar as complexas e cruéis implicações do silenciamento da mulher na construção/representação do mundo. Escutemos a "voz morta" de Penélope:

Muitas pessoas acreditam que a sua versão dos eventos é a verdadeira, coloca e retira alguns assassinatos, algumas sedutoras bonitas, alguns monstros de um olho só. Até eu às vezes acreditava nele. Eu sabia que ele mentia e inventava truques, apenas não imaginava que ele experimentaria seus truques e suas mentiras comigo. Não fui sempre a esposa fiel? Não esperei, e esperei, apesar da tentação - quase compulsão - de agir de outra forma? E qual o resultado disto, uma vez que a versão oficial se consolidou? Uma lenda edificante. ... Compreendi como muitas pessoas... estavam me transformando em uma estória, em várias estórias, embora não do tipo que eu teria preferido ouvir sobre mim mesma. O que pode fazer uma mulher quando uma fofoca escandalosa viaja pelo mundo? ${ }^{18}$

A complexa arquitetura do romance de Joyce é também um elemento importante na composição de Atwood. A estrutura narrativa principal - a versão de Penélope sobre sua vida - é engenhosamente mesclada com narrativas paralelas de coros anacrônicos que funcionam como interlúdios que tecem comentários sobre a ação central: são canções para crianças, baladas populares - algumas engraçadas, outras vulgares, burlescas, dramas da corte, até mesmo paródias de peças da tradição clássica.

\footnotetext{
${ }^{15}$ HOMER. The Odyssey, p. 17.

${ }^{16}$ PLATE. Is Contemporary Women's Writing Computational?, p. 52.

${ }^{17}$ ATWOOD. The Penelopiad, p. 3-4.

${ }^{18}$ ATWOOD. The Penelopiad, p. 2-3.
} 
É interessante observar um forte elemento de oralidade no romance de Atwood, que substitui convenções narrativas tradicionais por uma multiplicidade de vozes que cantam/(re)contam os eventos ligados a essa personagem clássica de forma inovadora. Essas canções nos remetem às tradições ancestrais de contar histórias e poemas (alguns deles tão longos como a própria épica homérica que sobreviveu vários séculos na tradição oral) e são fundamentais para resgatar a voz da mulher, excluída do processo de consolidação do saber/fazer da palavra escrita, sempre em poder do homem. Imagino que esta angustiante constatação deve ter sido a motivação da famosa afirmação de Jane Austen em Mansfield Park: "Não permitirei que os livros me provem nada. (...) a caneta sempre esteve nas mãos do homem."19

Penélope recria a épica de seu esposo a partir de sua "politics of location", para usar um termo importante da narratologia feminista; neste processo, ela reelabora o que foi narrado na Odisseia como as "relações ofensivas" dos pretendentes com as "impertinentes", "desleais" aias, cruelmente assassinadas por Odisseu. Atwood comenta sobre isto na Introdução do romance: "o que teria levado à execução das aias, e qual era a verdadeira intenção de Penélope? (...)Sempre senti-me perseguida por elas”.20

Em sua transmutação revisionista do épico clássico, o enforcamento dessas mulheres indefesas é caracterizado como um ato de terrível injustiça. Como serviçais leais, essas mulheres estavam obedecendo ordens de Penélope para "servir" os convidados, ao mesmo tempo que desempenhavam a função de "olhos e ouvidos entre os pretendentes", ${ }^{21}$ os quais as seduziram - ou estupraram, de acordo com a versão de Penélope; jamais saberemos, uma vez que essas mulheres foram condenadas e executadas sem o direito de falar em defesa própria.

O silêncio dessas mulheres é transformado por Atwood em uma canção de ninar executada pelo coro e dirigida a Odisseu; nesse criativo jogo narrativo, o herói homérico parece ter a capacidade de entender algumas verdades apenas quando transmitidas em forma de canção para crianças: "você tinha a espada/ você tinha a palavra/ sob seu comando". ${ }^{22}$ Ambos são símbolos fálicos: a força da palavra e a força física da arma mortal, em contraste com uma delicada canção, executada por jovens mulheres cujas vozes ecoam apenas a partir do mundo dos mortos.

Entretanto, como diriam os psicanalistas, o reprimido sempre retorna. O conceito de "abjeto" definido por Kristeva explora a fragilidade da construção do simbólico, o qual se funda numa perda inaugural, "matricida", e remete para esta força assustadoramente indefinível que desafia o ego, desrespeita fronteiras - "Abjeto. Algo rejeitado do qual não nos apartamos, do qual não se está protegido como nos protegemos de um objeto. Estranhamento imaginário e ameaça real, ele nos acena e termina por nos engolir" ${ }^{3}$ e que apenas a literatura pode tentar significar.

\footnotetext{
${ }^{19}$ AUSTEN. Mansfield Park, p.66.

${ }^{20}$ ATWOOD. The Penelopiad, p. XV.

${ }^{21}$ ATWOOD. The Penelopiad, p. 160.

${ }^{22}$ ATWOOD. The Penelopiad, p. 6.

${ }^{23}$ KRISTEVA. An essay on abjection.
} 
Em uma aula de antropologia dada pelos integrantes do coro, esse bárbaro assassinato é resignificado, adquirindo uma dimensão mitológica desafiadora:

Será que éramos sacrifícios rituais, sacerdotisas devotadas desempenhando nosso papel, primeiramente deliciando-nos em ritos orgiásticos de fertilidade com os pretendentes, depois purificando-nos ao nos lavarmos no sangue de nossas vítimas masculinas - pilhas deles, que honra para a Deusa! ... E o próprio enforcamento - pensem, caras mentes cultivadas, no significado desse enforcamento! Acima da terra, suspensas no ar, ligadas ao mar que é governado pela lua pela corda de uma embarcação - oh, existem muitas evidências que vocês não podem ignorar! ... Possivelmente nosso posterior estupro e o consequente enforcamento representam o extermínio do culto lunar matrilineal por um grupo de usurpadores bárbaros patriarcais, adoradores de um deus masculino. ${ }^{24}$

The Penelopiad nos dá um "pre-texto" para explicar o comportamento reservado de Penélope, que quase sempre desconfia da boa intenção das pessoas. Sua mãe, uma naiade, ${ }^{25}$ sempre foi fria e distante - uma imagem bem diferente da mãe altruísta, dedicada e sublime da ideologia patriarcal. Seu pai, longe de protegê-la como se espera de um pai, tenta afogá-la quando ela ainda era um bebê. Numa prosa um tanto sarcástica e cheia de desencanto, ela conversa com ela mesma sobre seu desconforto ao ser sempre descrita como sábia, pragmática, doméstica, melancólica, comparando-se desfavoravelmente com a glamorosa e ambiciosa Helena, cuja beleza e "lascívia descontrolada" havia arruinado a sua vida. Ela reconta a clássica narrativa das aventuras de Odisseu como se elas tivessem sido apenas "gossip" (fofoca) e notícias falsas que os admiradores dele queriam construir para engrandece-lo; e caracteriza Telêmaco como "um tecedor de falsidades como seu pai". 26

Penélope já havia sido "carinhosamente" advertida por seu esposo que, caso ela dormisse com outro homem, "ele ficaria sem dúvida muito aborrecido e me cortaria em pequenos pedaços com sua espada ou me enforcaria no telhado". Assim, sendo muito mais vulnerável que seu esposo, não havia muita alternativa para ela: "como tediosamente fiel eu tenho sido". ${ }^{27}$ Entretanto, a "verdade" nunca será conhecida; ela é complexa, escorregadia, proteana: "Nós dois éramos - e ambos admitimos isto - mentirosos competentes e desavergonhados."28

No seu ensaio Femininidade, Freud explica que a tecelagem, que para ele é uma contribuição feminina à civilização, teria sido uma consequência natural de nossa "deficiência genital"; ao tecer, afirma o patriarca da psicanálise, a mulher estaria repetindo em termos de artefato cultural a arte da natureza, que esconde com os pelos pubianos nossa vergonhosa ausência do pênis. A feminista americana Nancy Miller transforma radicalmente este conceito, introduzindo o conceito de "Aracnologia", segundo

\footnotetext{
${ }^{24}$ ATWOOD. The Penelopiad, p. 164-65 Para maiores informações sobre rituais sagrados de deusas, hábitos sexuais, sociedades matrilineais (não matriarcais) em sociedades ancestrais. Cf. STONE. When God was a woman, 1976.

${ }^{25} \mathrm{Na}$ mitologia grega, as Naiades são ninfas que presidiam as fontes, nascentes, córregos e lagos.

${ }^{26}$ ATWOOD. The Penelopiad, p. 137.

${ }^{27}$ ATWOOD. The Penelopiad, p. 74.

${ }^{28}$ ATWOOD. The Penelopiad, p. 173.
} 
o qual a história de Aracne. ${ }^{29}$ poderia ser resignificada como uma "parábola possível (ou modelagem crítica)de uma poética feminista (...) que busque na escrita uma subjetividade gendrada". ${ }^{30}$

Retomando a semântica da palavra texto e suas conotações de tecido, tecitura, textura, Miller propõe uma teoria que ela denomina hyphology, que vê o texto como "a tecitura de uma nova forma de resistência”. ${ }^{31} \mathrm{O}$ potencial transgressor dessa metáfora é admirável; assim como o trabalho aparentemente frágil e invisível desse pequeno "inseto" tem efeitos duradouros, a "mulher-escrita" 32 insinua-se de forma transformadora nos códigos estruturantes do patriarcado, buscando questionar, desafiar e transformar esses códigos.

A enaltecida fidelidade de Penélope homérica tem sido bastante debatida. O próprio Telêmaco duvida da fidelidade de sua mãe: "nunca um homem teve certeza de sua própria descendência. (...) dizem que sou o filho dele". ${ }^{33}$ Quando Telêmaco lamenta: "minha mãe tem o coração dividido", Pallas Athena - que, apesar de mulher, sempre reforça a sabedoria dos deuses - também compartilha dessa suspeição ancestral sobre a fidelidade da mulher: "Você sabe como é o coração de uma mulher. (...). Do seu querido senhor ela não mais se lembra, como se ele estivesse morto, e não pergunta mais nada que diga respeito a ele." ${ }^{34}$

A Penélope de Atwood problematiza o mito da fidelidade feminina que Homero reforça, ao narrar sua versão da "verdade":

\footnotetext{
${ }^{29}$ Em Teoria feminista e as filosofias do homem, p. 9-10, Andrea Nye desenvolve uma (re) tecitura de metanarrativas do patriarcado (como marxismo e psicanálise) a partir de uma perspectiva feminista. Ela inicia o livro com a história de Aracne, aqui brevemente resumida: Atena ... era ciumenta da lendária perícia de Aracne (...) Certo dia, Atena, disfarçada de anciã, veio espionar Aracne. Com voz de velha, instou a que Aracne reconhecesse a superioridade de Atena. Aracne, impaciente com essa intromissão, desdenhosa replicou que a própria Atena poderia vir, se quisesse, e elas veriam quem era a melhor tecelã. Diantes dessas palavras ... Atena jogou fora o disfarce e aceitou o desafio de Aracne. Os teares foram colocados lado a lado e ambas começaram a tecer - mas teceram motivos diferentes. Atena bordava os símbolos monumentais da soberania ateniense (...) Em cada canto acrescentava uma lição prática a Aracne (...) Todos haviam sido punidos por desafiar a autoridade dos deuses olímpicos. Aracne escolheu outro tema. (...) Ela descrevia, quadro após quadro, os crimes dos deuses olímpicos contra as mulheres. Mostrava Zeus como um touro arrastando Europa, como água raptando Aestérea, como cisne raptando Leda. Aracne não apenas mostrava os crimes de Zeus, mas também as vítimas chorosas dos lascivos Apolo e Poseidon. Sua tapeçaria descrevia sem piedade a brutalidade e trapaças dos homens e as súplicas lamentosas das mulheres, arrastadas para longe dos filhos, da família, da pátria. Atena olhou com ódio o trabalho de Aracne. Nem ela podia negar sua superioridade. Furiosa, arrancou a tapeçaria ofensiva, rasgou-a, reduziua a trapos, e pegando sua lançadeira bateu com ela repetidamente na cabeça de Aracne. Esta, atormentada, horrorizada, com a vida em perigo, pôs um laço em volta do pescoço em desespero. Logo, porém, que Aracne sentiu o laço apertando a garganta, Atena o afrouxou e a transformou numa aranha, pendurada num frágil fio por segurança (...) Renascida como a aranha, Aracne recomeçou sua tecelagem.

${ }^{30}$ MILLER. Arachnologies: The Woman, the Text, and the Critic, p. 272.

${ }^{31}$ MILLER. Arachnologies: The Woman, the Text, and the Critic, p. 282. Hyphos significa o tecido da teia da aranha.

${ }^{32}$ Em seu livro A mulher escrita, Lucia Castello Branco constrói a metáfora do feminino como renda, a qual, apesar de sua infinidade de formas e contornos - o "contorno de escrever" lacaniano -, não elimina o vazio. Ela caracteriza a escrita feminina como "lacunar", o que nos remete ao semiótico de Kristeva, ou mesmo ao pré-simbólico de Lacan.

${ }^{33}$ HOMER. The Odyssey, p. 7.

${ }^{34}$ HOMER. The Odyssey, p. 226.
} 
Sinto que devo tratar de vários aspectos das fofocas ofensivas que têm circulado nos últimos dois ou três mil anos. Essas histórias são completamente falsas. Muitos dizem que não há fumaça sem fogo, mas esse é um argumento tolo. Todos nós escutamos rumores que mais tarde mostram ser inteiramente sem fundamento, e acontece a mesma coisa com rumores sobre mim. As acusações a respeito de minha conduta sexual. Alega-se, por exemplo, que dormi com Amphinomus, o mais educados dos pretendentes.(...) Dizem que achei a conversa dele ... mais agradável que a dos outros, e isto é verdade; mas é uma longa distância daí para a cama. É também verdade que fui ambígua com os pretendentes e fiz promessas privadas para alguns, mas isto foi apenas uma estratégia. Entre outras coisas, usei meu aparente encorajamento para receber presentes caros deles - um parco retorno por tudo que eles tinham comido e gasto. ${ }^{35}$

A fala de Penélope nos remete ao tão debatido conceito do "efeito do real", segundo o qual a realidade, a "verdade", não estão em nenhuma estrutura ontógica dos objetos/ fatos, mas apenas nos significados, perspectivados historicamente, que damos às nossas experiências.

Metáforas sobre redes, teias, tecituras, abundam nas novas tecnologias de comunicação e informação da contemporaneidade. Neste sentido, retomamos o texto teórico-poético de Virginia Woolf, que desenvolve uma rica metáfora para problematizar as fronteiras entre teoria e narrativa, verdade estética e experiência:

A ficção, trabalho imaginativo que é, não cai como um seixo no chão, como talvez ocorra com a ciência; a ficção é como uma teia de aranha, mito levemente presa talvez, mas ainda assim presa à vida pelos quatro cantos. Muitas vezes a ligação mal é perceptível (...) essas teias não foram tecidas em pleno ar por criaturas incorpóreas, mas são obra de seres humanos sofredores e estão ligadas a coisas flagrantemente materiais, como a saúde e o dinheiro e as casas em que moramos. ${ }^{36}$

A Odisseia de Homero insere-se numa época em que a tradição escrita ainda se apoiava na rica produção oral, em que o mito era visto como um "magma discursivo", ${ }^{37}$ ainda não encapsulado por gêneros discursivos distintos; gradualmente, esses campos foram sendo delineados com mais precisão, fazendo surgir a "ilusão referencial" da história e seu distanciamento da literatura, no processo de institucionalização dessas áreas de conhecimento. Entretanto, a força do mito de Penélope ainda é surpreendentemente forte no mundo contemporâneo, apesar dos inegáveis avanços dos feminismos. Acreditamos portanto que o resgate/resignificação do mesmo a partir de uma perspectiva "gendrada" contribui de forma decisiva para a (re)criação de uma inovadora "tecitura penelopeana" mais questionadora dos fardos referenciais da tradição patriarcal, que represente a complexa intricada rede de experiência da mulher na sociedade contemporânea.

\section{A}

\footnotetext{
${ }^{35}$ ATWOOD. The Penelopiad, p. 144.

${ }^{36}$ WOOLF. Um teto todo seu, p. 55-6.

${ }^{37}$ LIMA. História, ficção, literatura, p. 15.
} 


\section{A B STR A C T}

Analysis of Homer's Penelope and Joyce's daring transformation of the classical personification of woman's quintessential loyal wife into the unfaithful, earthly, sexualized, trivial, lyrical, Molly Bloom. These two characters will be compared with a more contemporary recreation: Margaret Atwood's, in the novel The Penelopiad (2005). An important category for feminist and gender studies, voice/voicelessness is emphasized in our analysis; this female character, is both object of male-authored fiction (The Odyssey and Ulysses), and subject of the (un)weaving of a transgressive Penelopean "textile" (The Penelopiad). We also focus on the empowerment of "silence" in female narrative, through Molly's interior monologue and Atwood's Penelope, who speaks from the underworld. Kristeva's concepts of the "abject" and "semiotic language" inform our analysis, which counters the image of passivity of these apparently mute women, who nevertheless retain control over their lives.

\section{KEYWORDS}

Literatures in English, Gender, Psychoanalysis

\section{REFERÊNCIAS}

ATWOOD, M. The Penelopiad. Edingurgh: Canongate, 2005.

AUSTEN, J. (1814). Mansfield Park. $4^{\text {end }}$ ed. London: Colins, 1964.

BRENNAN, T. (Ed.). Between Feminism and Psychoanalysis. London: Routledge, 1989.

CASTELLO BRANCO, L.; BRANDÃO R. S. A mulher escrita. 2. ed. Rio de Janeiro: Lamparina, 1989.

CIXOUS, H. The Laugh of the Medusa. In WARHOL, R.; HERNDL, D. Feminisms. News Brunswick: Rutgers University Press, 1997, p. 347-362.

ELLMAN. R. Ulysses on the Liffey. London: Faber \& Faber, 1974.

ELLMAN. R. The Consciousness of Joyce. New York: Oxford Univ. Press, 1977.

GILBERT, S. James Joyce’s Ulysses. 4. ed. New York: Vintage Books, 1958.

FREUD, S. Femininidade. In: Obras completas de Sigmund Freud - Tomo X.

Trad. Odilon Galotti, Isaac Izecksohn e Gladston e Parente. Rio de Janeiro: Delta, [s.d.]. p. 117-141.

HARPER, K. J. When Women Were Priests. São Francisco: Harper San Francisco, 1995. HOMER. The Odyssey. In: The complete works of Homer, New York: The Modern Library. JOYCE, J. Ulisses. Trad. A. Houaiss. São Paulo: Editora Abril, 1980.

KRISTEVA, J. Women's time. In: WARHOL, R.; HERND, D. (Ed.). Feminisms. An anthology of literary theory and criticism. New Brunswick: Rutgers University Press, 1997. p. 860-79.

KRISTEVA, J. An Essayon Objection.//social.chars.ncsu.edu/wyrick/debclass/krist-fev. 2004. 
LEMAIRE, A. Introdução a Lacan. Trad. Durval Chechinato. Rio de Janeiro: Campus Editora, 1979.

LIMA, L. C. História, ficção, literatura. São Paulo: Companhia das Letras, 2006.

MILLER, N. Arachnologies: The Woman, the Text, and the Critic. In: MILLER, N. (Ed.). The Poetics of Gender. New York: Columbia University Press, 1986. p. 270-95.

MOI, T. (Ed.). The Kristeva Reader. Oxford: Basil Blackwell, 1986.

MCMULLEN, L. Same old Penelope: Feminist Analysis of Molly's Soliloquy in Ulysses. Disponível em: <www.publications.villanova.edu/Concept/2005>. Acesso em: 16 dez. 2007.

NYE, E. Teoria feminista e as filosofias do homem. Trad. Nathanael C. Caixeiro. Rio de Janeiro: Rosa dos Tempos, 1988.

PLATE, L. Is Contemporary Women's Writing Computational? Unraveling Twenty-first Century Creativity with Penelope at her Loom. Contemporary Women's Writing, v. I, n. 1/2, p.45-53, December, 2007.

ROISMAN, H. M. Penelope's Indignation. Transactions of the American Philological Association, v. 117, p. 59-58, 1987.

STONE, Merlin. When God was a Woman. London/New York: Harcurt Inc., 1976.

WOOLF, V. Um teto todo seu. Trad. Vera Ribeiro. Rio de Janeiro: Nova Fronteira, 1985. 